\title{
La estrategia editorial en torno al suceso: la invasión de Labort de 1636 en las imprentas hispanas
}

Javier Ruiz Astiz*

Artículo recibido:

27 de diciembre de 2019

Artículo aceptado:

15 de abril de 2020

Artículo de revisión

\section{Resumen}

Las relaciones de sucesos narran todo tipo de acontecimientos, desde fiestas y entradas reales hasta casos extraordinarios, pasando por crónicas diplomáticas y militares. Durante la Guerra de los Treinta Años proliferaron este tipo de impresos dando noticia de asaltos y batallas, como la invasión que se produjo en 1636 de la zona de Labort. Este hecho se difundió rápidamente por la península ibérica en forma de relaciones de sucesos, conservándose cinco ediciones distintas impresas en cinco ciudades españolas. Todas narran el mismo suceso, aunque muestran diferencias paratextuales en portada y otros elementos tipográficos y ornamentales, así como en parte del texto. Esto nos habla de la

* Universidade da Coruña, España

j.ruiz.astiz@udc.es

INVESTIGACIÓN BIBLIOTECOLÓGICA, vol. 34, núm. 85, octubre/diciembre, 2020, México, ISSN: 2448-8321 pp. 199-225 
estrategia editorial que siguió cada impresor, lo que se constatará a través del análisis material de cada una de las ediciones.

Palabras clave: Relaciones de Sucesos; Guerra de los Treinta Años; Labort; Imprenta

The editorial strategy around the event: Labort's invasion of 1636 in Hispanic printing

Javier Ruiz Astiz

\begin{abstract}
The news pamphlets narrate all kinds of events, from parties and royal entrances to extraordinary cases, through diplomatic and military chronicles. During the Thirty Years War, this type of print proliferated, reporting assaults and battles, such as the invasion that occurred in 1636 in the Labort area. This fact quickly spread throughout the Iberian Peninsula in the form of news pamphlets, keeping five different editions printed in five spanish cities. They all narrate the same event, although they show paratextual differences on the cover and other typographic and ornamental elements, as well as on parts of the text. This tells us about the editorial strategy followed by each printer, which will be verified through the material analysis of each edition.
\end{abstract}

Keywords: News Pamphlets; Thirty Years War; Labort; Printing

\title{
INTRODUCCIÓN
}

Dor todos es conocido que las relaciones de sucesos narran todo tipo de acontecimientos, desde fiestas y entradas reales hasta casos extraordina-
rios, pasando por crónicas diplomáticas y militares. De ahí que Víctor Infantes (1996: 203) afirmase sobre este tipo de impresos que "existir existen (y a miles)". No nos debe sorprender, por tanto, que durante la Guerra de los Treinta Años proliferasen este tipo de impresos dando noticia de asaltos y batallas. De este modo, resulta lógico que las relaciones que daban cuenta de 
hechos bélicos tuviesen un especial apogeo en la Europa de la primera mitad del siglo XVII, y más concretamente entre 1618 y 1648.

Inmersos en esta contienda se produjo en octubre de 1636 un hito de interés en el enfrentamiento entre la Monarquía Hispánica y Francia: la invasión de la zona de Labort (en francés Labourd, parte del actual País Vasco Francés) por parte de navarros y guipuzcoanos. Se pretende con este trabajo analizar la repercusión editorial que tuvo aquel suceso. Como se verá, dada la importancia de estos hechos se decidió plasmarlos en una relación que tuvo cinco ediciones el mismo año.

De este modo, junto a la información que detalla el texto, nos interesa mostrar la estrategia editorial del suceso, puesto que en 1636 (supuestamente entre noviembre y diciembre) aparecieron impresas tres relaciones bajo el mismo título en Pamplona, Valladolid y Barcelona. Las tres son idénticas, salvo algunas diferencias paratextuales en portada y otros elementos tipográficos y ornamentales, además de algunas variantes léxicas que se habrían producido en la fase de composición de las relaciones. Sin embargo, este mismo año en Valencia y Sevilla nos encontramos con dos relaciones que versan sobre el mismo acontecimiento pero que introducen ligeros cambios en título y contenido, sobre todo el texto valenciano.

Suele pensarse en este tipo de impresos como una propaganda perfectamente orquestada por las autoridades civiles de la época o diseñada desde los círculos de poder. ${ }^{1}$ Sin embargo, en esta ecuación se nos olvida el papel que jugaron otros actores; por un lado, los autores de aquellos relatos, ${ }^{2}$ pues se trataba de una literatura muy consumida por los lectores, aunque no debemos olvidar, por otra parte, el papel que jugaron los impresores. Estos últimos son los verdaderos olvidados de este engranaje, ya que ellos también anhelaban el éxito de sus impresos, puesto que les reportaba pingües beneficios. En consecuencia, no podemos obviar que los tipógrafos supieron aprovechar perfectamente tanto el tirón de un producto editorial como los sucesos más comerciales del momento (guerras, paces, matrimonios, exequias, terremotos, milagros, etc.).

En consecuencia, el objetivo central de este artículo será analizar los cinco impresos, pero no sólo teniendo en cuenta el contenido (lenguaje, variantes léxicas, etc.), sino que también se pretende estudiar el continente de dichos textos, para lo que se incidirá en todo aquello relacionado con la materialidad (composición, tipografía, elementos paratextuales y decorativos, etc.). Gracias a esto conseguiremos acercarnos a un producto editorial que

1 Sobre este aspecto reflexiona García Hernán (2011: 287).

2 Para profundizar sobre la figura de los distintos autores de relaciones de sucesos durante los siglos modernos merece la pena consultar el estudio de Pena Sueiro (2017: 494-498). 
tuvo tanto éxito en aquella coyuntura histórica, pero que, al mismo tiempo, resulta tan complejo de abordar.

Nuestro propósito va más allá de tratar estos impresos desde un prisma meramente literario o histórico, sino que resulta elemental para avanzar hacia un nuevo paradigma bibliográfico que nos acerque a este producto editorial. De este modo, siguiendo las pautas que enunció Fernández Valladares (1999: 109-110) -las cuales estamos desarrollando desde la Universidade da Coruña en el Catálogo y Biblioteca Digital de Relaciones de sucesos (CDBRS, https:// www.bidiso.es/CBDRS/)-, hemos llegado a la conclusión de que todavía hay muchos interrogantes por responder en torno a la génesis, composición, difusión y comercialización de un producto y género editorial tan variopinto como las relaciones de sucesos impresas durante los siglos XVI y XVII.

Dadas estas circunstancias, consideramos que este artículo persigue ahondar en la estrategia editorial emprendida por los tipógrafos al diseñar, componer y fijar la información sobre un papel en blanco, para después obtener un producto impreso que, además de reunir unas peculiaridades compositivas y materiales (Ruiz Astiz y Pena Sueiro, 2019: 376-377), tras largas jornadas de trabajo en los talleres era comercializado y distribuido entre los consumidores directos e indirectos de aquella sociedad áurea.

\section{Los Preparativos de la invasión: NaVArRa, PIEZa ClaVe}

El suceso que nos atañe en este trabajo tuvo lugar en un espacio fronterizo entre las dos potencias del momento: Francia y la Monarquía Hispánica. En la zona del sudoeste francés, concretamente en el Labourd, se dirimió una escaramuza militar protagonizada por navarros y guipuzcoanos. Un hecho realmente importante, pues Luis XIII de Francia era hijo de Enrique IV, y como tal también era rey de los territorios de la Baja Navarra y el Bearn, aunque, a su vez, ambicionaba recuperar la Navarra al sur de los Pirineos que había sido conquistada en 1512 por mandato expreso de Fernando el Católico.

Es en este enclave donde los navarros jugaron un papel relevante, pues por fuero solamente podían ser armados para defender sus propias fronteras, lo que provocó que esta aventura bélica que anhelaba tomar Bayona fuese un rotundo fracaso, ya que navarros y guipuzcoanos pronto abandonaron el frente de guerra al desertar para regresar a sus casas. Esto hizo que el virrey de Navarra, apurado por la situación, urgiese a Madrid para que enviase nuevas tropas a la frontera. Así, en una misiva del 6 de noviembre de 1636, señalaba al Consejo de Guerra: 
la gente de Navarra y de la Provincia no acostumbrada a campear ni a los trabajos de la campaña ni a las fortificaciones que se hacen para cerrar los cuarteles y obras de defensa se van yendo cada día no obstante cuantas diligencias se hacen para impedirlo, de manera que si no provee Su Magestad de gente pagada para estos puestos con mucha brevedad, no hay duda podrá el enemigo en ejecución sus intentos. (Archivo General de Simancas. Sección Guerra Antigua, Legajo 1171, fol. 36)

Entre las causas de aquel fracaso, Gallastegui Ucín (1990: 283-284) advierte otras circunstancias, caso de los escasos resultados obtenidos del saqueo de San Juan de Luz, el poco tacto que se tuvo con los habitantes de aquellas poblaciones, la premura de las lluvias de otoño que dificultaron la contienda y el fallecimiento de cientos de soldados navarros; todo esto hizo que dicha iniciativa se tornase en un error estratégico sin paliativos.

Las relaciones que se publicaron poco después, cuando la campaña ya se había mostrado como un rotundo error, trataron de ensalzar la vigorosidad y ardor de navarros y guipuzcoanos en la toma de Hendaya y su paso por Zocoa hacia Bayona. El relato es ese, el de una escaramuza en plena contienda de la Guerra de los Treinta Años que no llegó a buen puerto, pese a que el texto concluye con un supuesto cerco a Bayona, cosa que no era cierta, pues el propósito era tomarla para abrir otro frente en el sur de Francia y que éste, a su vez, despejase la zona norte para que las tropas acantonados en los Países Bajos pudieran avanzar y controlar Luxemburgo.

Pero resulta conveniente contextualizar aquella situación, ya que la entrada de Francia en la contienda militar provocó un nuevo e inesperado escenario para el reino navarro, pues como señala Coloma García (1995: 168), abrir un frente por el sur francés podía ocasionar una posible invasión de las tropas galas. Algo que se constata con cierto temor al año siguiente de la campaña para tomar Bayona, ya que en 1637 las Cortes navarras elevaron un memorial al virrey indicando su predisposición a defender las fronteras ante cualquier ataque desde tierras francesas, pero, al mismo tiempo, advirtieron de su firme posición sobre el respeto a los fueros ante cualquier acto que los violentase. $^{3}$

Esto podía ser una protesta encubierta por la desastrosa campaña de Labourd del año anterior por el marqués de Valparaíso, virrey de Navarra, Francisco González de Andía Irarrazábal. Como expuso Vázquez de Prada (2006: 106), durante el proceso de integración del reino en el seno de la Monarquía Hispánica, la función legislativa de las Cortes permitía a los Tres Estados oponerse a cualquier disposición procedente de Castilla que supusiese un contrafuero. Es aquí donde debe contextualizarse la incursión que 
en 1636 no contó con la aprobación de la Diputación, lo que enardeció la posición de las Cortes navarras unos meses después.

Sin duda, podemos afirmar que la causa principal de aquella escaramuza militar se debió a las noticias que llegaron a Madrid de la ofensiva llevada a cabo por el cardenal-infante, por lo que era necesario abrir otro frente militar contra Francia. En ese contexto se entiende la carta de Felipe IV al Reino, fechada el 15 de septiembre de 1636, en la cual podemos leer:

Muy reverendos nobles magníficos y bien amados míos, los avisos que han venido de los progresos que obran mis armas en Francia y de lo que conviene que el cardenal infante, mi hermano, tenga la asistencia necesaria para continuarlas con los buenos efectos que se pretenden obligan aquí por todas partes se intente la mayor diversión que fuere posible para lo qual he mandado al Marqués de Valparaíso, mi virrey y capitán general de ese reyno, execute en esas fronteras la empresa que le he mandado advertir y para que la consiga con mayor seguridad mediante la promptitud y valor con que habéis acudido en semejantes ocasiones os encargo que usando de vuestra fidelidad y celo de mi mayor servicio deis la gente y lo demás necesario que el Marqués os pidiere para que vaya a esta facción y para las que se ofrecieren de mi servicio y de vuestra defensa, enviándola con la prevención y en la forma conveniente porque con esta asistencia se aseguren los buenos sucesos en que espero recibir de vos muy agradable y particular servicio y de lo que dispusieredes me daréis cuenta para tenerlo entendido. (Archivo General de Navarra. Reino. Guerra, Legajo 2, núm. 87, fol. 1r)

Una vez recibida en Pamplona, y tras unos días, el 25 de septiembre le respondió el Reino en una misiva al monarca:

SCRM. Una carta de vuestra magestad de quince de este mes hemos recibido en que nos manda asistamos al Marqués de Valparaíso con la gente y lo demás necesariamente para la empresa que intenta contra Francia y para que en esta ocasión se conociera, lo que deseamos emplearnos en el servicio de vuestra magestad quisiéramos tener mano y poder para disponer la asistencia que pide el Virrey y es necesaria para la empresa esto toca al Reyno junto en Cortes y lo que podemos habemos ofrecerle al Marqués y es excusado cualquier ofrecimiento y diligencia cuando todo el Reyno está prevenido para servir en esta ocasión con particular deseo de mostrar el amor y fidelidad que debe a vuestra magestad continuando lo que ha hecho hasta aquí y respecto de pobreza y necesidad grande en que se halla causada de los donativos y armas que como a su costa y falta de comercio y otros accidentes es sin comparación más lo que hace agora que lo ha hecho en tiempos pasados no dexa de tener sacar de sus casas toda la gente que puede manejar a armas por quedar los lugares muy solos y este y otros inconvenientes habemos representado con celo del mayor servicio de vuestra magestad por no faltar a él y 
a lo que nos toca por obligación de nuestros oficios y siempre muy obedientes a cumplir las órdenes de vuestra magestad como estamos obligados. (Archivo General de Navarra. Reino. Guerra, Legajo 2, núm. 87, fol. 2r)

A lo que el rey le contestaba al Reino el 4 de octubre para que fuesen organizando el ataque a Labort y poniéndose a las órdenes del virrey de Navarra. En aquella respuesta se recoge lo siguiente:

Muy reverendos noble[s] magníficos y bien amados míos. Hase visto en la Junta de la Ejecución del Exército vuestra carta de veinte y cinco de septiembre en que representáis las veras con que procuráis acudir a mi servicio en la ocasión presente sintiendo que vuestras fuerças no correspondan a lo que en otras ocasiones habéis hecho y deseabades adelantaros en esta, y de vuestra fidelidad y obligaciones estoy cierto que sin embargo del estado presente de las cosas obraréis en esta ocasión con tanta promptitud y fineça que mediante vuestra demostración se consiga el efecto que se pretende quedando yo con memoria della para las que se ofrecieren de vuestra conveniencia y así os encargo que con todo cuidado dispongáis este servicio en la forma que os lo advirtiere el Marqués de Valparaíso del mi Consejo de Guerra, mi Virrey y Capitán General en ese Reyno, que en ello le hiciere muy agradable y particular y avisaréis lo que se ofreciere para tenerlo entendido. (Archivo General de Navarra. Reino. Guerra, Legajo 2, núm. 87, fol.3r)

Como puede verse la decisión ya estaba tomada, aunque, como relata Jiménez Moreno (2012: 181), fue en una reunión entre el Consejo de Estado y el de Guerra donde se acordó que fuese el marqués de Valparaíso y virrey de Navarra quien comandase el ataque a varias villas de Labort para terminar tomando Bayona. Tras los preparativos previos en la frontera navarra y guipuzcoana dispuso que la ofensiva comenzaría el 23 de octubre de 1636, como así nos lo indican las relaciones de sucesos conservadas.

\section{EL SUCESO Y SU REPERCUSIÓN EDITORIAL EN LA PENÍNSULA IBÉRICA}

Hecha esta contextualización de carácter histórico, vamos a centrarnos en lo que realmente nos interesa para esta investigación, que no es otra cosa que la repercusión que tuvo en las prensas hispánicas de la época tal suceso. Si las relaciones de sucesos relataban todo tipo de acontecimientos de la época (Pena Sueiro, 2001: 43-44), no podían faltar las crónicas de carácter militar. Así, entre 1618 y 1648 -durante la Guerra de los Treinta Años- proliferaron este tipo de impresos dando noticia de asaltos y batallas. Inmersos en esta contienda fue cuando se produjo en octubre de 1636, como ya hemos adelantado, la invasión de la zona de Labort. 
Dada la magnitud del evento se decidió plasmarlo en una relación que tuvo cinco ediciones (con ligeras diferencias) el mismo año. A simple vista, lo que nos llamó primero la atención fue que se editasen en cinco lugares tan dispares de la península ibérica cinco ediciones del mismo suceso, procedentes todas -como se mostrará- de la misma narración. De este modo, podemos apreciar que, supuestamente en 1636, se publicó la misma relación -aunque con variantes materiales y textuales- en Pamplona, Valladolid, Sevilla, Barcelona y Valencia.

Esto nos llevó a fijarnos en el interés que despertó el hecho de la toma y conquista de Hendaya y del lugar de Zocoa, pero también nos deja bien a las claras tanto el flujo informativo como la rapidez con la que circularon las noticias. Dicho esto, más allá de poder esclarecer las redes de información de principios del siglo XVII, lo que debemos resaltar es que un suceso -la invasión de la zona de Labort- se convirtió en cinco relaciones de sucesos editadas en distintos lugares de la península ibérica, por lo que son cinco ediciones distintas, pero que comparten el mismo texto.

Asimismo, este suceso -aún con sus variantes textuales y tipográficas- se erigió en un mismo producto, dadas las características tipográficas y materiales que, como se verá, reúnen todas ellas. Sin duda alguna, detrás de las cinco se encontraron sus impresores, quienes actuaron, a simple vista, como editores de estas relaciones al sacar al mercado un mismo producto editorial con multitud de similitudes, pero también con diferencias evidentes.

Ahora bien, cabe recalcar que se trata de cinco ediciones que, pese a las diferencias que manifiestan, resulta evidente que dan cuenta del mismo acontecimiento y beben de la misma información, por lo que procederían de un origen común. De ahí que se haga imprescindible pensar en distintas hipótesis a la hora de tratar de despejar la posible transmisión y composición de estas relaciones, aunque como apuntó Blecua (2001: 185-186), rastrear tales circunstancias resulte complejo dado el carácter efímero de este tipo de impresos. Aun con todo, y sin poder ser del todo concluyentes, cabe consignar cuatro hipótesis que se derivan del estudio bibliográfico -tanto material como textual- llevado a cabo:

1. Podríamos pensar en avisos manuscritos que habrían dado lugar a las relaciones editadas en cinco lugares diferentes. ${ }^{4}$ Esta opción es viable, aunque consideramos que no todas habrían surgido de avisos manuscritos, sino que pudo tratarse de una mezcla: una o dos surgirían de

4 No resulta extraño que los impresores estuviesen al tanto de noticias que llegaban a sus ciudades para tratar de publicarlas cuanto antes. Esto sucedió en numerosas ciudades, caso de Sevilla, Barcelona o Madrid. Véase sobre este aspecto el estudio de Bouza (2001: 166-167). 
dichos avisos y el resto se reproducirían tomando como referencia un texto impreso. Sin duda, la falta de testimonios manuscritos nos impide ver la circulación lógica del suceso, pues ninguna menciona al supuesto autor.

2. Derivado de la primera hipótesis, podemos mencionar que una relación pudo ser el embrión del resto, ${ }^{5}$ que en nuestra opinión sería la de Pamplona. El texto impreso en Navarra en el taller de Martín de Labayen ${ }^{6}$ habría pasado después a Valladolid y a Barcelona y, posiblemente, los surgidos en estas últimas se difundieron con posterioridad por Sevilla y Valencia. En consecuencia, el texto impreso original sería el pamplonés -lógico por la proximidad a los sucesos relatados y por el protagonismo de los navarros en aquella campaña militar-, y el resto derivarían de la relación publicada por Labayen, tal y como se expondrá en las próximas páginas, gracias a las distintas variantes textuales y compositivas que se advierten en las otras cuatro relaciones de sucesos.

3. En íntima relación con esta segunda hipótesis tendríamos la importancia de la estrategia editorial (como veremos en el próximo apartado) asumida por los impresores, de ahí que tratasen de diferenciar su producto -entendido éste como continente-, centrando sus esfuerzos en el contenido (texto), pese a que éste es prácticamente el mismo, aunque se advierten ligeras modificaciones o algunos añadidos. Dentro esta opción podemos destacar:

a) Sevilla procedería de Valladolid, de ahí que introduzca variantes (en título y texto) y frases novedosas (suprimiendo cosas de Valladolid y añadiendo nuevas) para poder imprimirse con licencia, pues era distinta a la de Valladolid. Así se diferenciaría el producto editorial, ya que el Consejo de Castilla actuaría -desde la Pragmática de $1558{ }^{7}$ sobre los impresos de Valladolid y Sevilla, pero no sobre los de Pamplona, por lo que de proceder del texto pamplonés no habría precisado de los cambios introducidos.

b) Valencia derivaría de Barcelona, pero introduce datos que tuvo que conocer por dos vías, bien a través de algún navarro presente en el taller de Miguel de Sorolla o porque el impresor tenía noticia (impresa o manuscrita) donde se daba cuenta de los párrafos finales que añade con datos relativos a Navarra, donde podemos leer que cifraba

5 La circulación de impresos era de tal magnitud desde finales del siglo XVI que no sorprendería que rápidamente se extendiesen por la península ibérica las novedades sobre la campaña de Labourd. Algo parecido ha sido analizado para el caso sevillano -en lo que a la recepción de noticias procedentes de Italia se refiere- por Espejo Cala (2015: 93-95).

6 Sobre el taller de Martín de Labayen puede consultarse el trabajo de Ruiz Astiz (2019).

7 Consúltese a este respecto el trabajo de Reyes Gómez (2000). 
en 15.000 los navarros que estaban cercando Bayona, un dato, este último, que ni mucho menos podía ser cierto.

4. Por último, todas las relaciones indican en su pie de imprenta que se publicaron en 1636, pese a que la de Valladolid no lo indica, quizás por omisión, pero sí aparece puesto "a mano", como puede verse en la Figura 2. Sin embargo, ¿se habrían impreso todas en 1636? Resulta complicado llegar a saberlo con certeza, aunque editar una relación tan breve podría haberse llevado a cabo en un día, pues todas -salvo la de Barcelona- constarían de un pliego doblado una vez. De ahí que una tirada de 500-700 ejemplares se podría realizar sin problemas en una jornada. Por tanto, si el suceso es de finales de octubre (entre el 15 y 23), para principios de noviembre podría estar la primera relación (la de Pamplona). Esta habría llegado a otras ciudades y entre finales de noviembre y el comienzo de diciembre podrían haberse editado las restantes. En caso de que Sevilla y Valencia derivasen de Valladolid y Barcelona, respectivamente, podrían haberse tirado para mediados-finales de diciembre. De este modo, consideramos que todas se habrían impreso en 1636 sin problema alguno.

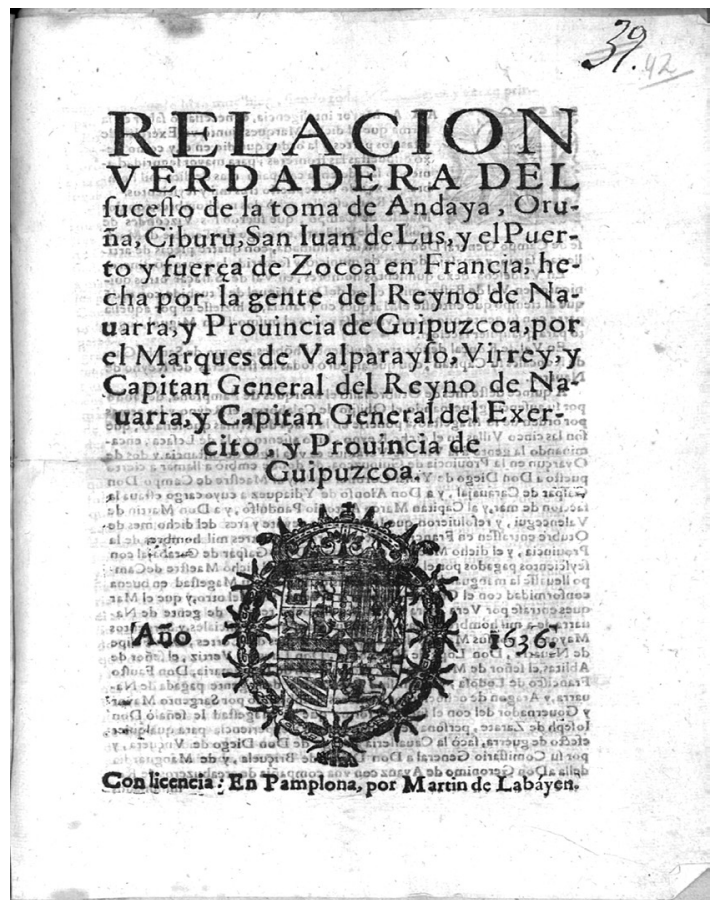

Figura 1. Relacion verdadera del sucesso... En Pamplona, por Martin de Labayen Fuente: Real Academia de la Historia: 9/3658-42 


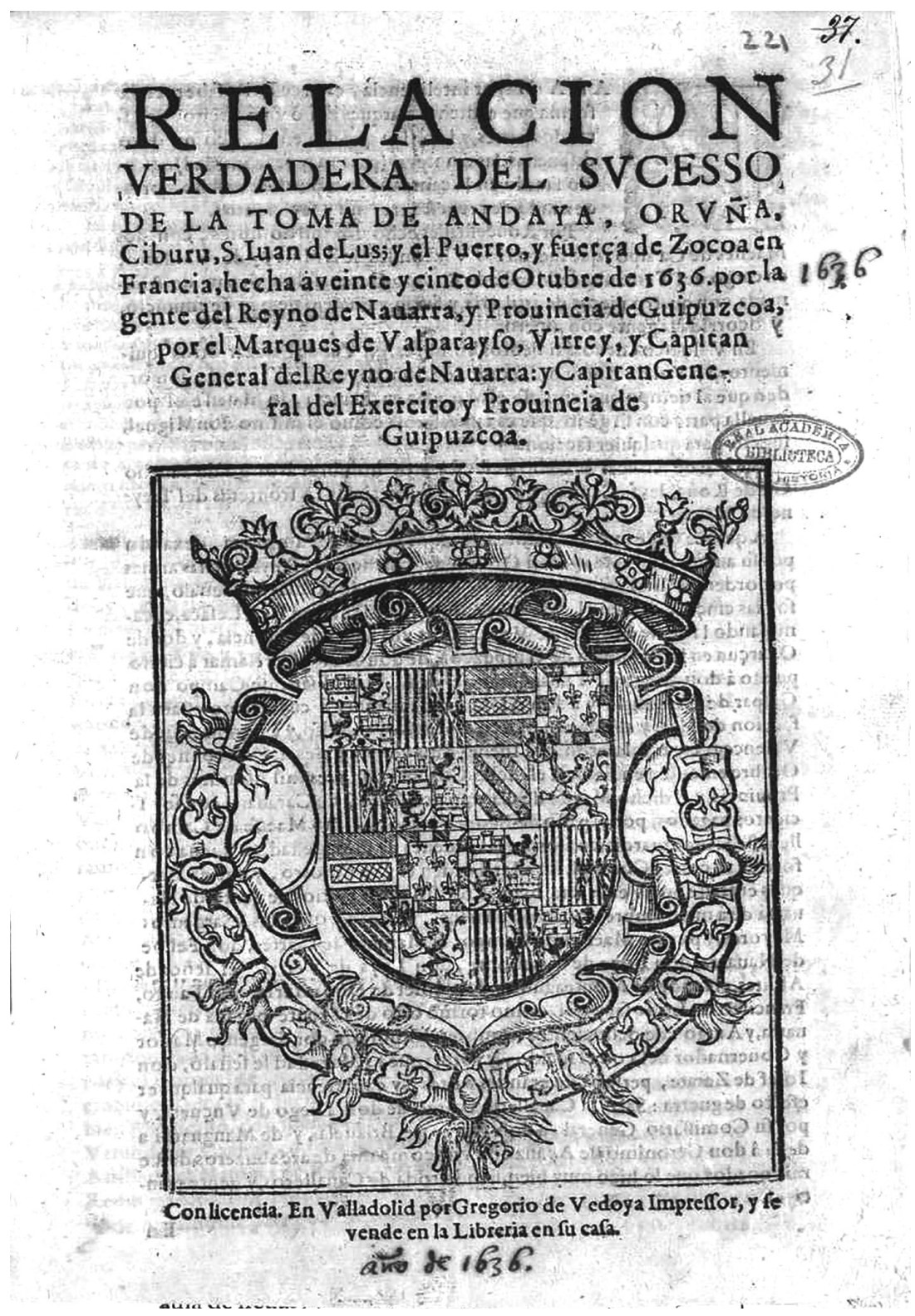

Figura 2. Relacion verdadera del sucesso... En Valladolid, por Gregorio de Vedoya Fuente: Real Academia de la Historia: 9/3719-31 


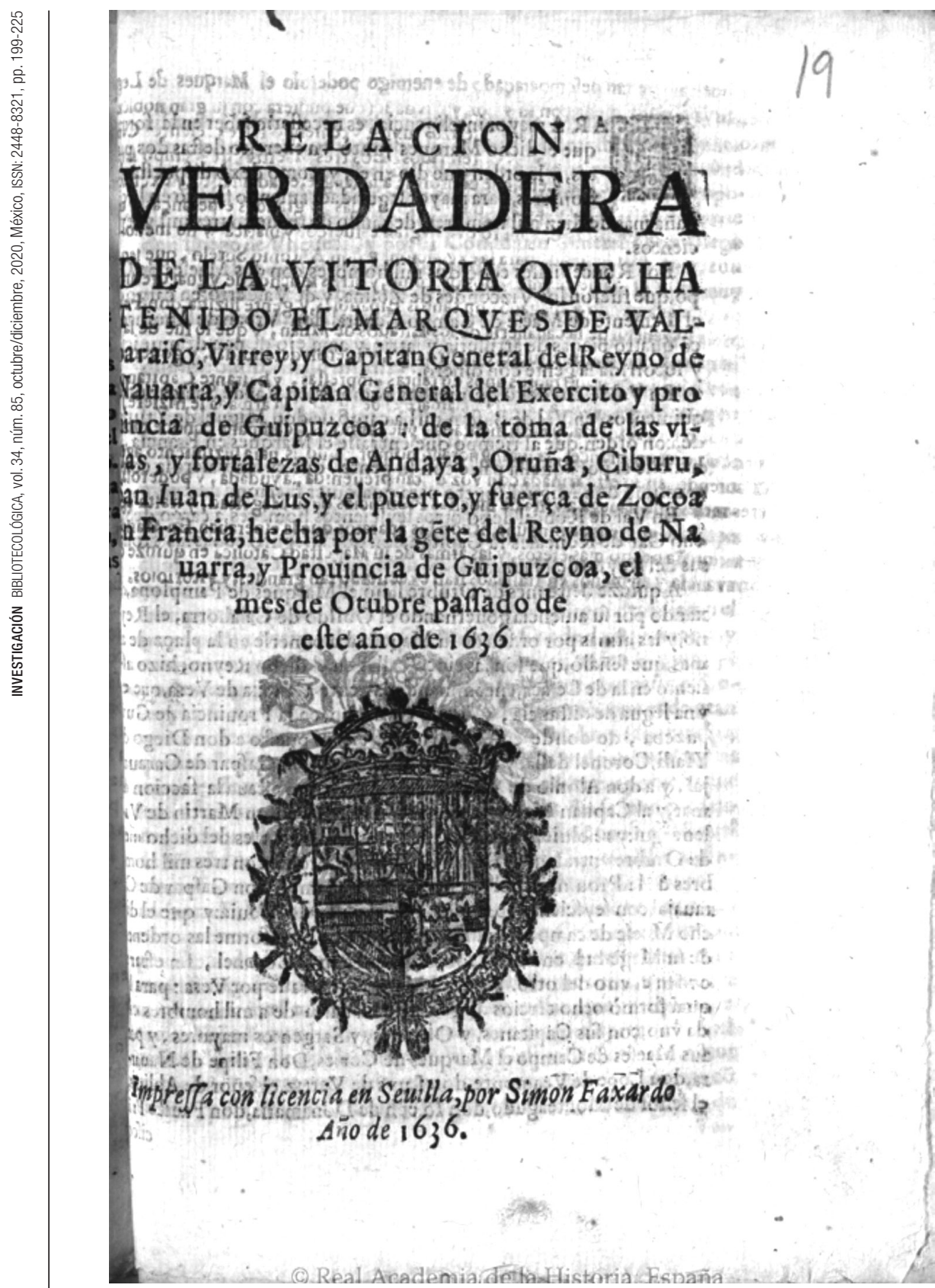

Figura 3. Relacion verdadera de la vitoria... En Sevilla, por Simon Faxardo Fuente: Real Academia de la Historia: 9/3489-19 


\section{RELACION \\ VERDA DERA, D E L} SVCESSO DE L A TO M A DE ANDAYA, ORVINA, CIBVRV; fan Iuan de Lus, y el puerto, y fuerça de Zocoa en Francia, hecha por la genite dell Reyno de Nauarra, y Prouincia de Guipuzcóa , por el Marques de Val-Parayfo, Virrey y Capitan General del Reyno de Nauarra, y Capitan General del exercito y Prouincia de Guipuzcoa.

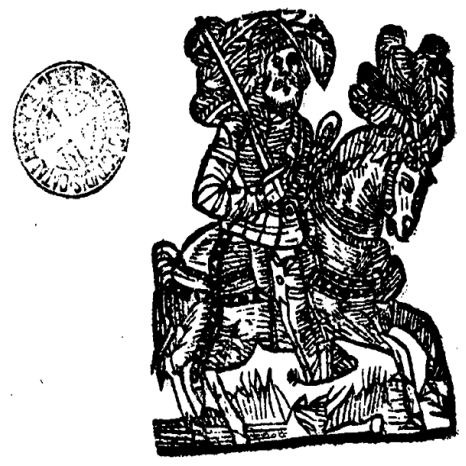

\section{Conlicencia en Barcelonas,}

Por Gabriel Nogues Impreffor del Reyno, en la calle de fanto Domingo. Año 163.60.

$$
119073
$$




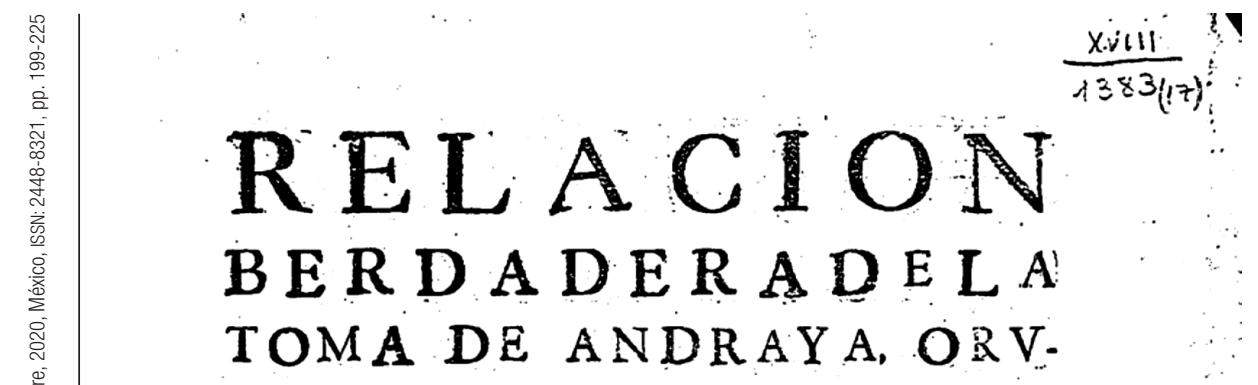

na, Giburu, San Iuan de Luss, y el Puerco y fuerça de Zocoa en Fran: cia,hecha por la gente del Rey no de Nauatra, y Prouincia de Gui . puzcoa, por el Marques de Valparayro, Virrey y Capitan Generâl del Reyno de Naturea, y Capiran General delExerciro y Pro uincia de Guipuzcoa. Con el numero de los Capi tanes Maeffes de campo del Rejro de Nauarsa.

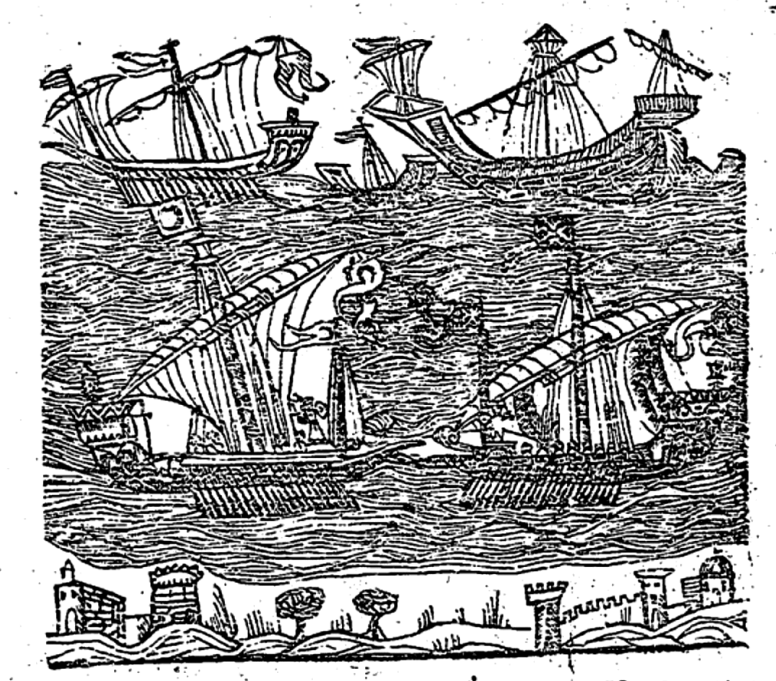

En Valencia por Miguel Sorolla junto al Eftudio General año mil feỹ cientos y treinta y feys.

Figura 5. Relacion verdadera de la toma... En Valencia, por Miguel Sorolla Fuente: Universitat de València: XVIII/1383(17) 
En resumen, lo que se constata es que el suceso de la invasión de Labort se difundió rápidamente -en apenas dos meses- por buena parte de la geografía hispana. Esto evidencia la rápida propagación de las noticias manuscritas e impresas en aquel contexto histórico. A falta de nuevos datos que sirvan para corroborar una u otra hipótesis, considero que la segunda, la tercera y la cuarta son realmente factibles, por lo que estaríamos ante un impreso editado primero en Pamplona del que se derivaron el resto de relaciones de sucesos, de ahí que se introdujesen variantes textuales y materiales de cierta consideración. Además, creemos que es bastante posible que se hubiesen editado las cinco entre noviembre y diciembre de 1636, así para principios de 1637 habrían salido al mercado cinco relaciones sobre el mismo suceso: la invasión del Labort francés.

Todo esto nos habla, sin duda, de la difusión de la información por la península ibérica, algo sobre lo que aún queda mucho por desentrañar, si bien es cierto que en un reciente trabajo Díaz Noci, Espejo y Baena (2018: 78-79) nos mencionan la más que posible colaboración entre impresores radicados en distintas ciudades para publicar un mismo producto, compartiendo así la edición. En nuestro caso esto no se produjo, sino que más bien se trataría de un proceso de copia siguiendo un impreso, ya que cada impresor adaptó el texto a sus necesidades y gustos. De ahí que se hubiese producido no ya la reimpresión o reedición, sino la readaptación de un texto a las exigencias editoriales de cada tipógrafo.

En el fondo, lo que sucedió con la relación editada en Pamplona por Martín de Labayen -de la que derivan las restantes: Valladolid, Sevilla, Barcelona y Valencia- no deja de ser el plagio que tan frecuente fue en el siglo XVII, ya que, como expone Rault (2006: 213), los impresores cuando actuaron como editores no tuvieron ningún tipo de reparo para reproducir (o copiar si se prefiere) una relación que había tenido éxito en otra ciudad. Pese a esto, lo habitual es que se introdujesen ligeras modificaciones, como sucede en los impresos que se analizan en este artículo, aunque también se constatan cambios y añadidos de mayor calado que serán desgranados en las próximas páginas.

\section{ESTRATEGIA EDITORIAL: LA INTERVENCIÓN DEL IMPRESOR}

Como indicaba Jaime Moll (1984: 63), una edición "es un conjunto de ejemplares de una obra, impresos de una composición única o que ofrece ligeras variaciones”. Dicho esto, podemos plantearnos: ¿qué opciones tenía un impresor a la hora de acometer la edición de una nueva relación de sucesos? Podría optar por editar un texto de un autor para ellos desconocido pero que 
versase sobre un acontecimiento relevante. Asimismo, cabría la opción de que decidiese publicar un texto exitoso copiándolo al pie de la letra, aunque, por otro lado, podría afrontar la edición de ese mismo relato noticioso pero introduciendo cambios y novedades de carácter textual y material.

Una vez esbozadas las cuatro hipótesis sobre la posible transmisión del impreso por la geografía española, no podemos obviar que la repercusión editorial que tuvo este suceso se debió a la intervención de ciertos impresores que decidieron editar tal acontecimiento. Esto nos evoca la estrategia que había detrás de las noticias impresas, pues si consideramos que el ejemplar pamplonés de Martín de Labayen fue el germen de todo, y que después éste se transmitió a otras ciudades, lo que vemos es cómo distintos tipógrafos adaptaron dicha relación, ${ }^{8}$ siguiendo fielmente el suceso, aunque con ligeras modificaciones, cambios de estilo, sustitución de unas palabras o frases por otras e, incluso, con añadidos.

De este modo, siguiendo a Blecua (2001: 47-48), tras la collatio pasaríamos a la examinatio y la selectio para tratar de fijar la filiación de los testimonios existentes. Así, la consulta de cada una de estas cinco relaciones ha permitido advertir las siguientes variantes, tanto materiales y narrativas como textuales. En total son siete, tal y como vamos a tratar de desentrañar a continuación. Por tanto, si consideramos que el texto base es el impreso de Pamplona, del mismo se derivarían las siguientes variaciones:

a) Añadidos

- Valladolid: en título incorpora "a veinte y cinco de otubre de 1636" y en el folio $2 r$ añade la palabra "dexar".

- Sevilla: en título pone, además, "de las villas y fortalezas” y "el mes de otubre pasado de este año de 1636”. Ya en el folio 2v añade distintas frases: "viendo se había rendido", "en la villa de", y "animada nuestra gente de rendir, y ganarle al francés por esta parte todas sus tierras".

- Barcelona: al final pone "Laus Deo".

- Valencia: en el título ya incorpora algo novedoso ("con el número de los capitanes, maeses de campo del Reyno de Navarra”). En el folio 1v pone "Iesus Maria", en el folio 2r añade tres líneas y las palabras “muy grande soldado”. Después en el folio 2v suma tres líneas nuevas y, al final, cinco párrafos novedosos.

8 Los problemas lógicos que se derivaban de la adaptación de un texto en prosa para su disposición en la caja de escritura en un taller de imprenta son muy interesantes, más si nos referimos a productos editoriales tan breves como la mayoría de las relaciones de sucesos. Véase Blecua (2001: 44). 
b) Omisiones

- Valladolid: en el folio 2r omite "Sancho".

- Sevilla: en el folio 2v omite "y conocido", después también una frase entera.

- Barcelona: omite "que" (también pasa en Valencia). En el folio 4r omite "y" y "de".

- Valencia: en el título omite "del suceso". Por último, en el folio 2v omite tras castellano "del castillo".

c) Cambios intencionados (forzados)

- Valladolid: pone en el folio 2v "uso" en vez de "usado".

- Sevilla: en el penúltimo párrafo del folio $2 \mathrm{v}$ introduce varias expresiones diferentes y una puntuación en frases distinta. Esto cambia algo el sentido del texto. A su vez, en el último párrafo de la relación se advierten ligeras modificaciones que alteran, en cierta medida, lo que pone en las otras relaciones.

- Barcelona: cambia "trabose" por "trabase" y en el folio 2r dice "compañía” en vez de "campaña”, como sucede en Pamplona, Valladolid y Sevilla. Después, en el folio 3r pone "por guarda" y no "manguardia", como apreciamos en las tres relaciones mencionadas anteriormente. Por último, cambia "en" por "su” y pone "está" y no "estaba" en el folio 3v, y en el folio $4 \mathrm{v}$ pone "satisfacción" como sucede en Valencia, en vez de "facción", que podemos leer en Pamplona y Valladolid. Cambia "en" por "su” y pone "está" y no "estaba" en el folio $3 \mathrm{v}$.

- Valencia: como sucede en Barcelona pone "compañía” y no "campaña". Luego dice "vanguardia” y no "manguardia”. A su vez, recoge en el último párrafo del folio 2v la expresión "satisfacción” y no "facción”, como he señalado para Barcelona. En el folio 1v pone "por lo" en vez de "para lo". Ya en el folio 2 r pone "que los que" y no "que a lo que", y pone "la vieron" y no "la vio" (como sucede en Barcelona).

d) Cambios sin intención

- Valladolid: en el folio 2r se advierten otras formas de escribir "Ciburo" en vez de "Ciburu". Hay también alternancias vocálicas ("rindió") y consonánticas ("poderlo"). Por último, en el folio $2 \mathrm{v}$ pone "mensagero" y "habra" sin "h". Esto se repite en Barcelona y Valencia.

- Sevilla: como sucede en Pamplona hay palabras con "b" o "v" que cambian en otros textos. Hay, a su vez, alternancia vocálica y conso- 
nántica dentro del propio texto, ya que aparece "poderlo" y "podello". - Barcelona: aparecen palabras escritas de diferente manera con "b", "v", "ç", “y”, "i" o "z". Recoge (como en Valencia) "octubre" en vez de "otubre". Aparecen también alternancias vocálica y consonántica. Por último, cabe mencionar que pone "h" delante de "a" en verbos compuestos.

- Valencia: en este apartado se asemeja mucho al texto de Barcelona, pese a que en los tiempos verbales compuestos no siempre pone "ha".

e) Errores tipográficos

- Valladolid: en el folio $2 \mathrm{r}$ pone un "?" cuando no toca. Del mismo modo, se puede leer "saquer", en vez de "saquear".

- Sevilla: en el folio 1v pone "Alonlo" al confundir la "l" con la "s". Después, en el folio $2 \mathrm{r}$ podemos leer "sele" sin separación. Y ya en el folio $2 \mathrm{v}$ encontramos tres maneras de componer el término Zokoa: "Zocoa", "Cocoa" y "Gocos".

- Barcelona: en el folio 2r pone "Ahumeda" y no "Ahumada". En el folio 2v leemos "Boeuia" en vez de "Beouia", y en el folio 3r, por error o mala lectura, pone "Roda" y no "Rada", así como "Lacaun" en vez de "Leçaun". Aparece también "señallaron" con doble "l".

- Valencia: en la portada vemos que pone "Andraya" y no "Andaya". En el folio 1v se aprecia "Ahumeda" y no "Ahumada". Se lee "Boenia" y no "Beouia". Leemos también "Ayan" y no "Ayanz". Por último, en el folio 2v alterna en el mismo folio "Ciburu" y "Ciburo".

f) Características de composición

Todas muestran una portada organizada del siguiente modo: título, escudo o imagen, y pie de imprenta. Por lo demás, en texto todas recurren a abreviaturas y espacios acusados para la composición de la plana, y todas ellas (salvo Pamplona y Sevilla) incorporan elementos decorativos.

- Valladolid: en el título pone "S.Iuan" en vez de "San Juan".

- Sevilla: introduce en el título varias diferencias y añadidos, como se ha advertido ya.

- Barcelona: en el título pone todo igual a Pamplona salvo "Val-Parayso".

- Valencia: presenta en el título algunas omisiones y añadidos, así como formas diferentes de escribir ciertas palabras. 
g) Características de ejemplar

- Valladolid: en esta relación en el folio 1v pone "ocorrida" porque le falta la "s" por mal entintado. En este mismo folio podemos leer "prin-“ y "cipal” en la línea siguiente, pero no se lee bien, aunque se intuye que hay trazos, debido, sin duda, a mal entintado. Después en el folio $2 \mathrm{r}$ apreciamos nuevamente mal entintado en palabras como "puente" y "de". A su vez, en este mismo folio se constata una mala composición de la caja de escritura que hace que haya dos tipos desplazados hacia arriba.

Todo esto nos evoca claramente la estrategia editorial que siguió cada impresor para acometer la edición de cada una de estas relaciones. Como hemos constatado, más allá de la información que detalla el texto, nos ha interesado mostrar la estrategia que hay detrás del suceso de Labort, puesto que en 1636 (supuestamente entre noviembre y diciembre) aparecieron impresas tres relaciones bajo el mismo título en Pamplona, Valladolid y Barcelona. Se comprueba que las tres son idénticas, salvo algunas diferencias paratextuales en portada y otros elementos tipográficos y ornamentales, además de algunas variantes léxicas que se habrían producido en la fase de composición de las relaciones. Sin embargo, este mismo año en Sevilla y Valencia nos encontramos con dos impresos que versan sobre el mismo acontecimiento pero que introducen ligeros cambios en título y contenido, sobre todo el texto valenciano.

Por tanto, podemos afirmar que los impresores sabían perfectamente qué necesitaban para atraer la atención del público, no ya sólo por el contenido informativo de sus relaciones de sucesos, sino que también tenían en cuenta la forma en que presentaban el relato y, a su vez, cómo lo representaban. Esa conjugación de continente (materialidad y representación del relato impreso) y contenido (noticia o suceso narrado) explica que los cinco impresores que decidieron estampar un texto sobre la invasión de Labort en 1636 recurriesen a unas tácticas compositivas muy similares, ya que la cara externa de aquellos impresos jugaba un papel sumamente relevante para cautivar a los posibles lectores. Esto, que ya fue advertido por Ettinghausen (2006: 25) para el título que solían disponer los tipógrafos, invadía el resto del impreso, yendo más allá de la portada, tal y como se comprueba en este caso.

De este modo, consideramos que por lo expuesto en este trabajo queda patente que la intervención de cada impresor cobraba una capital importancia a la hora de componer el texto editado, jugando con las palabras (omitiendo, suprimiendo o modificando algunas), añadiendo frases enteras e, incluso, introduciendo novedades de índole material. En especial, como sugiere Blecua (2001: 185), esto pudo cobrar un mayor protagonismo para lo 
que se conoce como pliegos sueltos - dentro de los que se englobarían las relaciones de sucesos-, ya que pese a presentar problemas de índole textual similares a los libros, también es cierto que mostraron ciertas diferenciaciones.

Estas casuísticas procedían del menor espacio disponible, por lo general un pliego de dos o cuatro hojas, como mucho ocho, por lo que el impresor-editor se veía en la obligación de ajustar el texto informativo al pliego, es decir, a la caja de escritura. De ahí que, en ocasiones, el tipógrafo se viese obligado a acortar o suprimir algunas frases ante la falta de espacio, aunque existen casos en los que se aprecia la inserción de imágenes u otro tipo de elementos al final porque les sobraba parte del pliego y no querían dejarlo en blanco.

En definitiva, el papel de los impresores que ejercieron, a su vez, como editores, no era exclusivamente el de trasladar de forma literal un texto manuscrito o impreso a sus prensas para publicar un relato noticioso idéntico, sino que advertimos su mano detrás de todas aquellas variantes textuales y compositivas que dieron forma a los productos que salían de sus prensas. Esto es lo que se constata en el presente artículo, ya que en 1636 cinco impresores -Martín de Labayen, Gregorio de Bedoya, Simón Fajardo, Gabriel Nogués y Miguel Sorolla- radicados en distintas ciudades (Pamplona, Valladolid, Sevilla, Barcelona y Valencia) estamparon en sus respectivos talleres un texto que relataba el avance de las tropas navarras y guipuzcoanas en el sudoeste de Francia. Resumiendo, se trata de un total de cinco ediciones diferentes que versan sobre el mismo relato, pero que pese a sus variantes textuales conforman, como veremos, un producto editorial idéntico.

\section{ANÁLISIS MATERIAL DE LAS RELACIONES}

Uno de los propósitos de este artículo, junto a la repercusión del suceso en la España de la época y a su estrategia editorial, es el análisis de los cinco impresos, pero no sólo teniendo en cuenta el contenido (lenguaje, variantes léxicas, etc.), sino que también se pretende estudiar el continente de dichos textos, para lo cual se incidirá en todo aquello relacionado con la materialidad (composición, tipografía, elementos paratextuales y decorativos). Gracias a esto conseguiremos acercarnos a un producto editorial que tuvo tanto éxito en aquella coyuntura histórica, pero que, al mismo tiempo, resulta tan complejo de abordar.?

9 Se perciba o no como un producto y/o género editorial, lo cierto es que aún queda mucho por aclarar en torno a las relaciones de sucesos, aunque a esclarecer el panorama ha venido un reciente análisis de Ruiz Astiz y Pena Sueiro (2019: 375-379). 
Dejando a un lado las variantes advertidas, debemos prestar atención ahora a la materialidad de las relaciones estudiadas. Primero vamos a detenernos en algunos aspectos característicos de la composición material de estos impresos, para lo que se ha confeccionado la Tabla 1. De ella podemos entresacar algunos datos de interés, de los que sobresale la relación de sucesos como producto, puesto que, a pesar de sus ligeras diferencias, las cinco ediciones guardan una estrecha similitud entre ellas en cuanto a continente, ya que son concebidas por distintos impresores del mismo modo.

Señaladas estas peculiaridades en lo que a su composición material se refiere, debemos advertir que las disposiciones legales también solían afectar a este tipo de impresos, aunque por lo visto en este caso su impacto fue mínimo, puesto que, pese a que todas cumplen en algunos aspectos la Pragmática de $1627^{10}$-disponiendo en el pie de imprenta de sus respectivas portadas los datos mínimos exigidos, si bien el texto de Valencia no indica la licencia en portada para indicarla en el colofón-, no afectan en gran medida a su composición material, ya que ninguna relación inserta la licencia de impresión entre sus paratextos legales, ${ }^{11}$ como era práctica habitual en otro tipo de impresos, pero no tanto en lo que a las relaciones de sucesos hace referencia. De este modo, vemos que las disposiciones legales (muy probablemente) no eran tenidas en cuenta en su totalidad para tratar de abaratar los costes de edición de un producto editorial tan demandado como las relaciones.

\begin{tabular}{|l|c|c|c|c|c|}
\hline & Pamplona & Valladolid & Sevilla & Barcelona & Valencia \\
\hline Formato & Folio & Folio & Folio & $4^{\circ}$ & Folio \\
\hline Extensión & {$[4] \mathrm{p}: 1 \mathrm{r}-2 \mathrm{v}$} & {$[4] \mathrm{p}: 1 \mathrm{r}-2 \mathrm{v}$} & {$[4] \mathrm{p}: 1 \mathrm{r}-2 \mathrm{v}$} & {$[8] \mathrm{p}: 1 \mathrm{r}-4 \mathrm{v}$} & {$[4] \mathrm{p}: 1 \mathrm{r}-2 \mathrm{v}$} \\
\hline Típo de letra ${ }^{12}$ & $\begin{array}{c}\text { Atanasia } \\
(99-100 \mathrm{~mm})\end{array}$ & $\begin{array}{c}\text { Atanasia } \\
(89-90 \mathrm{~mm})\end{array}$ & $\begin{array}{c}\text { Texto } \\
(110 \mathrm{~mm})\end{array}$ & $\begin{array}{c}\text { Texto } \\
(120 \mathrm{~mm})\end{array}$ & $\begin{array}{c}\text { Miñona } \\
\text { o Glosilla } \\
(50 \mathrm{~mm})\end{array}$ \\
\hline Portada & Sí & Sí & Sí & Sí & Sí \\
\hline Pie de imprenta & Sí & Sí & Sí & Sí & Sí \\
\hline Colofón & No & No & No & No & Sí \\
\hline Reclamos & Sí & Sí & Sí & Sí & Sí \\
\hline Abreviaturas & Sí & Sí & Sí & Sí & Sí \\
\hline Espacios acusados & Sí & Sí & Sí & Sí & Sí \\
\hline Letra capitular & Sí & Sí & Sí & Sí & Sí \\
\hline Elementos decorativos & No & Sí & No & Sí & Sí \\
\hline
\end{tabular}

10 Sobre esta cuestión puede consultarse el trabajo de Reyes Gómez (1999: 328).

11 Esto era sumamente habitual como relatan en sus trabajos Bouza (2018: 126), y Martín Molares (2017: 377).

12 Tipo de letra según la clasificación de Carter (1999: 195-196). 


\begin{tabular}{|l|c|c|c|c|c|}
\hline Mayúsculas en portada & 2 tipos & 3 tipos & 3 tipos & 3 tipos & 3 tipos \\
\hline Minúsculas en portada & 1 tipo & 1 tipo & 1 tipo & 1 tipo & 2 tipos \\
\hline
\end{tabular}

Tabla 1. Materialidad de las relaciones: composición

Al margen de estos aspectos compositivos, en la Tabla 2 hemos querido acercarnos algo más a la materialidad de estas relaciones, al analizar la distribución de la plana en cada uno de estos impresos. Así podemos constatar que todas, a excepción de Barcelona por su formato en $4^{\circ}$, guardan una estrecha similitud, aun con sus divergencias, como es evidente y lógico.

\begin{tabular}{|c|c|c|c|c|c|}
\hline & Pamplona & Valladolid & Sevilla & Barcelona & Valencia \\
\hline $\begin{array}{c}\text { Caja } \\
\text { escritura: } \\
\text { portada }\end{array}$ & $\begin{array}{l}12 \text { líneas } \\
\text { + Escudo } \\
+1 \text { línea }\end{array}$ & $\begin{array}{l}10 \text { líneas } \\
+ \text { Escudo } \\
+2 \text { líneas }\end{array}$ & $\begin{array}{l}13 \text { líneas } \\
+ \text { Escudo } \\
+2 \text { líneas }\end{array}$ & $\begin{array}{l}11 \text { líneas } \\
\text { + Escena } \\
+3 \text { líneas }\end{array}$ & $\begin{array}{l}10 \text { líneas } \\
+ \text { Escena } \\
+3 \text { líneas }\end{array}$ \\
\hline $\begin{array}{c}\text { Caja } \\
\text { escritura: } \\
\text { texto }\end{array}$ & $\begin{array}{c}47 \text { líneas } \\
\text { (46 texto } \\
\text { y } 1 \text { reclamo). } \\
\text { Fol. } 2 \mathrm{v}: 27 \\
\text { líneas de } \\
\text { texto. }\end{array}$ & $\begin{array}{c}49 \text { líneas } \\
\text { (48 texto } \\
\text { y } 1 \text { reclamo). } \\
\text { Fol. } 2 v \text { : } 23 \\
\text { líneas de texto } \\
\text { y Escena. }\end{array}$ & $\begin{array}{c}42 \text { líneas } \\
\text { (41 texto } \\
\text { y } 1 \text { reclamo). } \\
\text { Fol. } 2 \mathrm{v} \text { : } 42 \\
\text { texto. }\end{array}$ & $\begin{array}{c}29 \text { líneas } \\
\text { (28 texto } \\
\text { y } 1 \text { reclamo). } \\
\text { Fol. } 4 \mathrm{r}: 26 \text { líneas } \\
\text { texto, } \\
2 \text { líneas viudas } \\
\text { y } 1 \text { reclamo } \\
\text { (29 líneas). } \\
\text { Fol. } 4 \mathrm{v}: 8 \text { líneas } \\
\text { texto, } 1 \text { sin } \\
\text { cubrir, } 2 \text { Laus } \\
\text { Deo, } \\
3 \text { sin cubrir } \\
\text { y Escena. }\end{array}$ & $\begin{array}{c}51 \text { líneas } \\
\text { (50 texto } \\
\text { y } 1 \text { reclamo). } \\
\text { Fol. 1v: } \\
4 \text { decoración, } \\
1 \text { sin cubrir, } \\
3 \text { IESUS MARIA, } \\
1 \text { sin cubrir, } \\
41 \text { texto } \\
\text { y } 1 \text { reclamo. } \\
\text { Fol. } 2 \text { v: } 36 \text { texto } \\
1 \text { sin cubrir, } \\
1 \text { imprimatur, } \\
1 \text { sin cubrir } \\
\text { y } 1 \text { nombres. }\end{array}$ \\
\hline $\begin{array}{l}\text { Línea viuda } \\
\text { capitular }\end{array}$ & Sí & Sí & No & No & No \\
\hline $\begin{array}{l}\text { Línea viuda } \\
\text { texto }\end{array}$ & No & No & No & Sí & No \\
\hline $\begin{array}{c}\text { Espacio } \\
\text { debajo de } \\
\text { letra capitular }\end{array}$ & Sí & No & No & Sí & Sí \\
\hline
\end{tabular}

Tabla 2. Materialidad de las relaciones: distribución de la plana

De este modo, por ejemplo, podemos ver el enorme parecido que tienen las cinco portadas de las relaciones estudiadas, ya que en todas ellas apreciamos una estructura similar: enunciado del título (10-13 líneas), un escudo de la 
Monarquía Hispánica o una escena militar ${ }^{13} \mathrm{y}$, por último, el pie de imprenta (1-3 líneas). Esto nos evidencia, como queda patente, una concepción similar - pese a tratarse de cinco talleres de imprenta alejados los unos de los otrosa la hora de diseñar un producto y género editorial tan exitoso entre los siglos XVI y XVII.

No obstante, de las relaciones estudiadas -entendidas todas ellas como producto fruto de una única composición y, por ende, de un diseño concreto-, constatamos que todas ellas varían de un taller a otro, algo lógico en la época de la imprenta manual, lo que nos habla bien a las claras del grado de intervención del impresor. Este es uno de los aspectos que ha pretendido esclarecer esta investigación; la adopción de un texto en un determinado taller de imprenta y las distintas soluciones encontradas por cada tipógrafo para publicar un mismo relato. De esta manera, lo que se ha constatado no es sólo que introdujesen cambios en el texto con nuevas expresiones o, incluso, frases enteras, sino que principalmente intervinieron en la conformación de ese texto adaptándolo a una caja de escritura concreta, al formato del pliego, al tipo de letra y a otros elementos que afectaban directamente a la materialidad del producto impreso.

Más allá de la calidad tipográfica y compositiva de las relaciones estudiadas -pues Corbeto y Garone (2015: 75) sugieren que el siglo XVII constituyó una etapa de regresión en lo que a la calidad material y editorial de los impresos se refiere, fruto de las guerras en el continente europeo-, lo que nos vuelve a poner de manifiesto el análisis de estos cinco impresos es la estrategia editorial de los tipógrafos: un suceso (la invasión de Labort) se produce (del manuscrito al impreso), se publica sucesivamente en diferentes ciudades y, finalmente, se difunde y comercializa de cinco maneras distintas, aunque todas guarden una íntima relación

\section{Conclusiones}

Entre los siglos XVI y XVII se fue gestando, tal y como sugiere Bouza (2018: 139), una esfera pública fruto, entre otros motivos, de la difusión de relaciones

13 Este tipo de motivos en las portadas de las relaciones de sucesos fueron habituales, sobre todo cuando se trataba de relatos bélicos, como el que nos ocupa en este estudio. Debido a esto, el hecho de que se editase un texto relacionado con el enfrentamiento militar que tenían Francia y España en el continente europeo explica que los tipógrafos tratasen de identificar sus impresos con los avatares de la monarquía, bien con su escudo (incorporando a Portugal por aquellas fechas) en tres ocasiones o a través de escenas belicistas (con una batalla naval y la figura de un caballero) en las dos restantes. 
de sucesos. En esta difusión jugaron un papel sumamente relevante los impresores, quienes edificaron un entramado sociocultural en el que las noticias se convirtieron en una realidad cotidiana. En este contexto es donde debemos insertar las cinco relaciones de sucesos que se editaron a finales de 1636 en otras tantas ciudades de la Monarquía Hispánica, vertebrando así el territorio peninsular de norte a sur y de este a oeste.

Tras advertir a lo largo de este trabajo las peculiaridades que encierran las distintas ediciones que se publicaron en España en 1636 sobre la toma de Hendaya y el intento de cerco a la ciudad de Bayona, cabe cerrar este artículo indicando que:

1. Se constata el éxito editorial que tuvieron en la España del siglo XVII las relaciones de sucesos como impresos portadores de noticias, y más en la coyuntura bélica de la Guerra de los Treinta Años, cuando se difundieron un sinfín de textos de carácter militar dando cuenta de los éxitos y, en menos ocasiones, de los fracasos de la Monarquía Hispánica en el tablero europeo. De este modo, hemos apreciado el modo en que una escaramuza de escasa entidad -como la invasión de Labort- circuló rápidamente a los meses de haber acontecido por toda la geografía peninsular.

2. A su vez, se ha evidenciado que existía un tráfico de noticias que nos deja entrever la transmisión de las mismas, bien fuesen manuscritas o impresas. Lo cierto es que entre los flujos comunicativos hispanos sobresalían Madrid, Sevilla y Barcelona, pero al margen de estos grandes polos informativos se ha mostrado que hubo otros, caso de Valencia, Pamplona y Valladolid, que también tuvieron su protagonismo en las redes noticieras que se tejieron por toda la península ibérica.

3. Se ha mostrado lo interesante que resulta prestar atención desde la bibliografía tanto a la materialidad de aquellos impresos (denominados menores) como a su contenido textual. Gracias a esto, hemos comprobado que continente y contenido estaban estrechamente relacionados, por lo que resulta imprescindible estudiar la noticia (la información), pero sin olvidarnos que el relato se adaptaba a una caja de escritura y a las condiciones existentes por un taller (letrería, estado de las prensas, pericia de los operarios, etc.). Esto nos permite afirmar que, tal y como hemos apreciado del estudio material y textual efectuado en este artículo, cada imprenta condicionaba el resultado final.

4. Por último, aunque unido a lo anterior, no resulta menos interesante el hecho de que este trabajo ha pretendido sumergir al lector en el papel ejercido por los impresores -y sus subalternos- en la composición y diseño de un producto editorial tan complejo como las relaciones 
de sucesos. De lo evidenciado por las variantes textuales advertidas podemos concluir que los tipógrafos, aunque no fuesen los autores de aquellos relatos noticiosos, sí ejercieron un considerable grado de interferencia sobre los textos que finalmente publicaban: adaptando, modificando, suprimiendo y añadiendo lo que consideraban oportuno.

En suma, gracias a los cuatro aspectos que se han consignado, entre otras cosas, consideramos que este artículo viene a ser una aproximación que ha pretendido acercarnos al papel que desempeñaron los tipógrafos a la hora de editar relatos noticiosos, mostrando, a su vez, el engranaje y funcionamiento de aquel entramado comercial en el que circularon y se intercambiaron las noticias con una clara finalidad mercantilista. Esto es lo que ha tratado de conseguir esta investigación; mostrar, gracias a un ejemplo concreto, el modo en que intervinieron los impresores -cuando ejercían también como editores- no sólo en el tráfico de noticias, sino principalmente en el contenido informativo (texto) y en el continente (materialidad) de las relaciones de sucesos que sacaron de sus prensas en la España áurea.

Agradecimientos

El presente artículo se ha realizado en el marco del Programa de Doctorado en Ciencias de la Documentación en la Universidad Complutense de Madrid. El autor forma parte del grupo de investigación HISPANIA (G000208) de la Universidade da Coruña, enmarcándose en el Proyecto I+D+I Biblioteca Digital Siglo de Oro 6 (BIDISO 6), con referencia PID2019105673GB-100, financiado por el Ministerio de Ciencia e Innovación del Gobierno de España para el periodo que va desde el 01/06/2020 al 31/05/2023.

\section{REFERENCIAS}

Blecua, Alberto. 2001. Manual de crítica textual. Madrid: Castalia.

Bouza, Fernando. 2001. Corre manuscrito. Una historia cultural del Siglo de Oro. Madrid: Marcial Pons.

Bouza, Fernando. 2018. "El pueblo desea las noticias. Relaciones de sucesos y gacetas entre propaganda y esfera pública en la España de los Austrias". Hemeroteca Municipal de Madrid (1): 111-143.

Carter, Harry. 1999. Orígenes de la tipografía. Punzones, matrices y tipos de imprenta (siglos XV y XVI). Madrid: Ollero \& Ramos. 
Coloma Gracía, Virginia. 1995. "Navarra y la defensa de la monarquía en los reinados de Felipe III y Felipe IV (1598-1665)”. Príncipe de Viana 56 (204): 163-182.

Corbeto, Albert y Marina Garone. 2015. Historia de la tipografía. La evolución de la letra desde Gutenberg hasta las fundiciones digitales. Lleida: Milenio.

Díaz Noci, Javier. 2004. "Fuentes históricas coetáneas de la liberación de Hondarribia: la construcción de un acontecimiento en la España de Olivares”. Mediateka (10): 77-107.

Díaz Noci, Javier, Carmen Espejo y Francisco Baena. 2018. "Redes y empresas informativas en España: conexiones de impresores y editores de prensa en el siglo XVII". Barcelona Quaderns d'Historia (25): 75-85.

Espejo Cala, Carmen. 2015. "La circulación de las noticias en España a finales del siglo XVI. Relaciones de sucesos de Rodrigo de Cabrera (1595-1600) sobre las guerras turcas”. Estudios sobre el mensaje periodístico 21 (1): 89-103.

Ettinghausen, Henry. 2006. "Tabloids y Broadsheets: la prensa española y sus lectores en el primer tercio del siglo XVII", en Las relaciones de sucesos. Relatos fácticos, oficiales y extraordinarios, editado por Patrick Bégrand, 17-33. Besançon: Université de Franche-Comté.

Fernández Valladares, Mercedes. 1999. "Los problemas bibliográficos de las relaciones de sucesos algunas observa-ciones para un repertorio descriptivo (con un nuevo pliego poético del siglo XVI)", en La fiesta: actas del II Seminario de Relaciones de Sucesos, editado por Sagrario López Poza y Nieves Pena Sueiro, 107-120. A Coruña: Sociedad de Cultura Valle Inclán.

Gallastegui Ucín, Javier. 1990. Navarra a través de la correspondencia de los virreyes (1598-1648). Pamplona: Gobierno de Navarra.

García Hernán, David. 2011. "Guerra, propaganda y cultura en la Monarquía Hispánica: la narrativa del Siglo de Oro". Obradorio. Revista de Historia Moderna (20): 281-302.

Infantes, Víctor. 1996. “¿Qué es una relación? Divulgaciones varias sobre una sola divagación”, en Las relaciones de sucesos en España: 1500-1750, editado por Henry Ettinghausen, Víctor Infantes, Augustín Redondo y María Cruz García de Enterría, 203-216. Madrid: Universidad de Alcalá de Henares.

Jiménez Moreno, Agustín. 2012. “Opciones estratégicas de la monarquía española a comienzos de la guerra contra Francia (1636-1638): la propuesta de Marco Antonio Gandolfo". Chronica Nova (38): 177-202.

Martín Molares, Mónica. 2017. "Paratextos legales en las relaciones de sucesos impresas entre 1550 y 1650", en Doce siglos de materialidad del libro: estudios sobre manuscritos e impresos entre los siglos VIII y XIX, editado por Manuel José Pedraza Gracia, 365-383. Zaragoza: Prensas Universitarias de Zaragoza.

Moll, Jaime. 1984. "Aproximaciones a la sociología de la edición literaria”, en La edición de textos, editado por Pablo Jauralde, Dolores Noguera y Alfonso Rey, 61-68. Londres: Tamesis.

Pena Sueiro, Nieves. 2001. "Estado de la cuestión sobre el estudio de las Relaciones de sucesos". Pliegos de bibliofilia (13): 43-66.

Pena Sueiro, Nieves. 2017. "Los autores de relaciones de sucesos: primeras precisiones", en La invención de las noticias: las relaciones de sucesos entre la literatura y la información (Siglos XVI-XVIII), editado por Giovanni Ciappelli y Valentina Nider, 491-508. Trento: Università degli studi di Trento. 
Rault, Didier. 2006. "Genealogía de las relaciones dedicadas a la batalla de Nördlingen (1634)”, en Las relaciones de sucesos. Relatos fácticos, oficiales y extraordinarios, editado por Patrick Bégrand, 199-217. Besançon: Université de Franche-Comté.

Reyes Gómez, Fermín de los. 1999. "Los impresos menores en la legislación de imprenta (siglos XVI-XVIII)”, en La fiesta, editado por Sagrario López Poza, 325 338. A Coruña: Sociedad de Cultura Valle Inclán.

Reyes Gómez, Fermín de los. 2000. El libro en España y América: legislación y censura (siglos XV-XVIII). Madrid: Arco Libros.

Ruiz Astiz, Javier. 2019. "En Pamplona se imprimen relaciones de sucesos: el taller de Martín de Labayen (1636-1648)", en Festina lente. Augusta empresa correr a espacio: studia in honorem Sagrario López Poza, editado por Nieves Pena Sueiro y Carlota Fernández Travieso, 263-296. A Coruña: Universidade da Coruña.

Ruiz Astiz, Javier y Nieves Pena Sueiro. 2019. "Presentación. Las relaciones de sucesos: producto y género editorial en la Monarquía Hispánica”. Memoria y civilización (22): 371-380.

Vázquez de Prada, Valentín. 2006. "El proceso de integración de Navarra en la Monarquía Hispánica (siglos XVI-XVII)", en Navarra: memoria e imagen, editado por Mercedes Galán, María Larraza y Eduardo Oslé, 99-120. Pamplona: Eunate.

\section{Para citar este texto:}

Ruiz Astiz, Javier. 2020. "La estrategia editorial en torno al suceso: la invasión de Labort de 1636 en las imprentas hispanas". Investigación Bibliotecológica: archivonomía, bibliotecología e información 34 (85): 199-225. http://dx.doi.org/10.22201/iibi.24488321xe.2020.85.58234 